\title{
AS TEORIAS DO CONHECIMENTO: A FUNDAMENTAÇÃO EPISTEMOLÓGICA DAS CIÊNCIAS HUMANAS
}

KNOWLEDGE THEORIES: THE EPISTEMOLOGICAL RATIONALE OF HUMAN SCIENCES

\author{
SILVESTRI, Kátia Vanessa Tarantini \\ ${ }^{1}$ Centro Universitário da Fundação Hermínio Ometto - FHO, Araras/SP, Brasil
}

\begin{abstract}
RESUMO: Toda ciência repousa sobre uma metodologia. Não é diferente com as Ciências Humanas. Cada metodologia tem uma fundamentação epistemológica que a define. Esse artigo tem como objetivo possibilitar uma visão tanto cronológica/histórica quanto essencialista sobre os referencias teóricos, metodológicos e epistemológicos das Ciências Humanas. Não obstante, contribui para uma visão pluralista da realidade e do conhecimento. A metodologia adotada é bibliográfica. Uma revisão de literatura de temas relacionados as principais teorias do conhecimento é apresentada com ênfase no inatismo, na metafísica, no racionalismo, no empirismo, criticismo e fenomenologia. Os resultados esperados são o conhecimento das relações internas, críticas e avanços acerca das bases epistemologicas das ciências humanas até a contemporaneidade. A fim de contextualizar, o exemplo da Psicologia é apresentado, enfatizando a importância da criticidade e responsabilidade face às metodolgias, pois com um objeto de estudo tão complexo como o ser humano, as ciências humanas devem estar sempre alertas acerca das metodologias adotadas.
\end{abstract}

Palavras-chave: filosofia da ciência, metodologias, psicologia.

\begin{abstract}
All science rests on a methodology. It is no different with the humanities. Each methodology has an epistemological foundation that defines it. This article aims to provide a chronological / historical as well as essentialist view on the theoretical, methodological and epistemological references of the Human Sciences. Nevertheless, it contributes to a pluralistic view of reality and knowledge. The methodology adopted is bibliographic. A literature review of themes related to the main theories of knowledge is presented with emphasis on inertia, metaphysics, rationalism, empiricism, criticism, and phenomenology. The expected results are the knowledge of internal realities, criticisms and advances on the epistemological bases of the human sciences up to the present time. In order to contextualize, the example of Psychology is presented, emphasizing the importance of criticism and responsibility towards the methodologies, because with a study object as complex as the human being, the human sciences must be always alert about the methodologies adopted.
\end{abstract}

Keywords: philosophy of science, methodologies, psychology.

\section{INTRODUÇÃO}

As teorias do conhecimento e seus métodos desenvolvem-se com o estudo do ontos (ser) já com os pré-socráticos e toda a Filosofia posterior se desenvolve, até a nossa contemporaneidade, num constante diálogo entre os filósofos. Entre os métodos que compreenderemos, dois se destacam como o eixo crucial desse percurso: o racionalismo (inatismo) e empirismo (realismo). Entenderemos ainda a crise das ciências e chegaremos até 
a resposta fenomenológica husserliana à crise das ciências que como veremos será também uma crise da razão/da subjetividade.

A linha histórica traçada é específica aos objetivos aqui delineados. Dos séculos VI a. C. ao século XX d. C., portanto, dos filósofos pré-socráticos aos filósofos contemporâneos, veremos Heráclito e Parmênides; representando os socráticos (séc. VI a.C.), Platão (428/427348/347 a.C.) e Aristóteles (384 a.C. - Atenas, 322 a.C.). Dos modernos Descartes (1628 a 1649 auge de suas publicações), Bacon (1597, 1612 e 1625, são anos de intensa publicação), Locke (entre 1689-1693 suas principais obras são publicadas), Hume (1739 a 1757 publica regularmente) e Kant (1747 a 1798 tem inúmeros livros publicados). Do início da contemporaneidade Edmund Husserl (de 1887 a 1936 publica intensamente). Nesse percurso, alguns outros pensadores entraram nesse diálogo para compor o raciocínio como os mestres da suspeita, tal qual nomeou o filósofo Ricouer (1977), a respeito das filosofias de Kierkegaard (1840 a 1850 produz intensamente), Nietzsche (1872 a 1888 todas suas obras foram publicadas), Marx (em 1872 tem sua obra principal publicada) e Freud (1900 a 1940 publica intensamente). Por fim, veremos, como exemplo, a Psicologia e suas relações com as teorias do conhecimento.

O objetivo desse artigo é possibilitar um entendimento maior acerca das bases epistemológicas das ciências humanas a partir das principais teorias do conhecimento. Com efeito, o eixo crucial desse artigo é o entendimento das metodologias presentes nas diferentes teorias do conhecimento, destacando algumas das mais relevantes para o estudo do racionalismo, do empirismo, do criticismo e da fenomenologia. A metodologia adotada é bibliográfica, uma revisão de literatura é feita a partir dos grandes referencias como Heráclito (1996), Parmênides (1996), Platão (2015), Aristóteles (1997), Descartes (1997), Bacon (1996), Husserl (2008), entre outros.

\section{DESENVOLVIMENTO}

\section{A teoria do conhecimento pré-socrática}

Toda a história da filosofia pode ser desdobrada a partir de dois grandes filósofos présocráticos, Heráclito (1996) e Parmênides (1996). Chama-se filosofia pré-socrática o período anterior ao vivido por Sócrates e denominado período socrático. Os filósofos pré-socráticos têm uma linhagem que remonta ao século VI a.C. O objeto de estudos dos pré-socráticos era a physis (aquilo que se revela) e buscam a arkhe (origem/princípio) de todas as coisas. Com efeito, Tales, Anaximandro, Pitágoras, Demócrito, Anaxímenes, Leucipo, Empédocles, Zenão, Anaxágoras, Heráclito e Parmênides são os primeiros filósofos, pois:

A filosofia grega parece começar com uma ideia absurda, com a proposição: a água é a origem e a matriz de todas as coisas. Será mesmo necessário deter-nos nela e levála a sério? Sim, e por três razões: em primeiro lugar, porque essa proposição enuncia algo sobre a origem das coisas; em segundo lugar, porque o faz sem imaginação e fabulação; enfim, em terceiro lugar, porque nela embora apenas em estado de crisálida, está contido o pensamento: ‘Tudo é um'. (NIETSZCHE, 1987, p. 16).

O que Nietzsche (1987) está nos dizendo é que os filósofos pré-socráticos buscaram explicar a realidade não mais de forma mítica, fabulosa ou unicamente empírica, mas antes, buscaram a origem, o princípio como fundamento, o ser das coisas. Essa mudança na forma de investigação é a origem da Filosofia. 
Heráclito (1996) e Parmênides (1996), representantes principais do período présocrático ocorrido entre os séculos VI-V a. C. destacam-se no desdobramento futuro da filosofia ao serem retomados ou criticados por Platão (2015) e Aristóteles (1997) no período socrático, ocorrido entre os séculos V. a.C. a IV a.C.

Chamamos de teoria do conhecimento as filosofias dos pré-socráticos, mas devemos estar cientes que na época não havia ainda essa nomenclatura que surge na modernidade. Fazer epistemologia é, por um lado, compreender as diversas teorias do conhecimento e, por outro, analisar os critérios, a aplicabilidade, a eficácia e eficiência da ciência.

Comecemos por Heráclito (1996) que procurava compreender a multiplicidade das coisas, isto é, dos seres. Sua filosofia afirmava que todas as coisas estão em constante mudança. Daí a famosa frase, "tu não podes descer duas vezes no mesmo rio, porque novas águas correm sempre sobre ti" (Heráclito, 1996, p.32). Para Heráclito, o ser é constituído de oposições internas, ou seja, o ser é e não é ao mesmo tempo. Por esse motivo afirmava o filósofo présocrático que só se mantém o fluxo constante, o movimento. O termo devir, tão difundido na história da filosofia, remonta, portanto, a Heráclito. Veremos que Aristóteles (1997) negará esse princípio heraclitiano, porém, no século XX a lógica dialética elaborada por Hegel (1982) e depois por Marx (1982), por exemplo, encontra sua intuição já em Heráclito.

Já Parmênides (1996) começou criticando Heráclito afirmando que é absurdo uma coisa ser e não ser ao mesmo tempo. Para tanto Parmênides estabelece o princípio da não contradição: o ser é e o não ser não é. Isso significa dizer que o ser é único, imóvel e infinito. Todavia, o movimento das coisas, dos seres, não é negado por Parmênides que reconhece que nascem, crescem e morrem. Sua teoria defendia que o movimento somente existe no mundo sensível, sendo a percepção uma ilusão dos sentidos fundada na doxa (opinião) e, por esse motivo, nada confiável. Por essa negativa, Parmênides afirmava que somente o mundo inteligível era confiável. Com essas proposições a identidade entre o ser e o pensamento é criada por Parmênides, pois pensamos o que é e não pensamos o que não é, o não ser.

Com os exemplos de Heráclito e Parmênides pode-se notar o nascimento da filosofia como linguagem conceitual para a compreensão da realidade e não mais a linguagem simbólica como faziam os mitos. Em outras palavras, passa-se de um pensamento cosmogônico (mitos) para um pensamento cosmológico racional (filosofia). O pensamento pré-socrático será revisto pelos filósofos socráticos.

\section{A teoria do conhecimento do período socrático.}

Platão (2015) e Aristóteles (1997), respectivamente mestre e discípulo, são os dois filósofos que nos interessam na trajetória proposta de compreensão das teorias do conhecimento. Suas filosofias são as grandes bases de toda a história futura do pensamento filosófico. São como o tronco que sustenta a enorme árvore dos sistemas filosóficos.

Por cronologia iniciemos com Platão e o mundo das ideias. Quem já não ouviu algo sobre a Alegoria da Caverna? Pois bem, ela representa as etapas da educação do filósofo de sair do mundo das sombras (aparências/fenômenos) e alcançar o mundo verdadeiro (do conhecimento/inteligível).

Platão cria o que se chama de ascensão dialética (a dialética platônica). Diz ele existir a opinião (doxa) formada por imagens sensíveis/realidades sensíveis e a ciência (episteme) constituída pelo conhecimento matemático, pelo raciocínio hipotético, pelo conhecimento filosófico e pela intuição intelectiva (noesis). Dessa lógica, Platão estabelece a comentada distinção entre o conhecimento sensível e o conhecimento inteligível. 
O mundo sensível é o mundo dos fenômenos e o mundo inteligível o das ideias. De um lado, afirma Platão, que o mundo sensível é ilusório; percebido pelos sentidos; local da multiplicidade; pura sombra do verdadeiro mundo - o inteligível. Por outro lado, afirma que o mundo inteligível é quando a inteligência se eleva das coisas múltiplas e mutáveis para as ideias unas e imutáveis. Não obstante, Platão ainda diz existir uma hierarquia entre as ideias, de forma que no topo está a ideia de Bem que para Platão é a beleza máxima. Como atingimos o mundo inteligível? Responde Platão, pela contemplação e pela depuração dos enganos dos sentidos. Eis que a teoria da participação é desenvolvida. Platão explica que os fenômenos só existem na medida em que participam do mundo das ideias. Notamos que o mundo das ideias é o ser parmenediano e o mundo dos fenômenos é o ser heraclitiano. Porém ainda nos resta a questão: como é possível ultrapassar o mundo sensível até o inteligível?

Platão supõe o espírito puro e, dessa suposição, cria-se a teoria da reminiscência. $O$ Espírito já teria contemplado o mundo das ideias e esqueceu-se quando se degenera prisioneiro do corpo. Desse contexto, origina-se a famosa frase platônica que parafraseio: "o corpo é o cárcere da alma". Em sua filosofia fica evidente que conhecer é lembrar, conhecer é reconhecer. Os sentidos são somente, diz Platão, uma forma de despertar na alma as lembranças adormecidas. Vale salientar que a semântica de alma para os gregos antigos traz o sentido de inteligência, ânima ou daimon - a voz interior. Conforme Platão,

\footnotetext{
A alma é pois, imortal; renasceu repetidas vezes na existência e comtemplou todas as coisas existentes tanto na Terra como no Hades e por isso não há nada que ela não conheça! Não é de espantar que ela seja capaz de evocar à memória a lembrança de objetos que viu anteriormente, e que se relacionam tanto com a virtude como com as outras coisas existentes. Toda a natureza, com efeito, é uma só, é um todo orgânico, e o espírito já viu todas as coisas; logo, nada impede que nos lembremos de uma coisa - o que nós homens, chamamos de "saber" - todas as outras coisas acorram imediata e maquinalmente à nossa consciência [...] toda investigação e ciência são apenas simples recordação. (PLATÃO, 2015 p. 85).
}

Platão faz uma síntese entre as filosofias de Heráclito e de Parmênides. Concorda com Heráclito acerca do mundo sensível que é instável, se modifica. De Parmênides, Platão concorda com a estabilidade e imutabilidade, que na filosofia platônica corresponde ao mundo inteligível. Portanto, o método platônico é a dialética, oposição de ideias.

Já com Aristóteles (1997) Parmênides é criticado ao julgar como enganoso o mundo sensível. Todavia, Aristóteles funda a metafísica retomando alguns dos conceitos de Parmênides como o do princípio da identidade, a saber, A=A. Desta forma, o movimento dos seres (das coisas) é compreendido por Aristóteles como sendo a própria essência a multiplicidade e a mudança física. Ou seja, a essência está na própria coisa e não em um mundo inteligível, conforme Platão. E para conhecer as essências não é necessária nenhuma dialética como em Platão. Aristóteles diz que basta conhecer as próprias coisas. Com efeito, o eterno é o próprio movimento dos seres/coisas. Sua crítica a Heráclito se dá justamente acerca do movimento. Lembremos que Heráclito dizia que tudo flui o tempo todo. Mais precisamente, afirmava que todas as coisas mudam sem cessar; que o que temos diante de nós em dado momento é diferente do que foi há pouco e do que será depois. Com a influência de Parmênides, Aristóteles diz que um ser não pode ser e não ser ao mesmo tempo, eis um segundo princípio, o de contradição: A é e não é A. Heráclito fere a esse princípio lógico segundo Aristóteles.

Contra Parmênides, Aristóteles critica a afirmação que o ser é imóvel. Pois como vimos Aristóteles dirá que o movimento está na essência dos seres. E contra Platão critica as imutabilidades das essências. Para Aristóteles os acidentes não mudam a substância dos seres. 
Por exemplo, a raça de uma vaca não muda a substância vaca, isto é, o que faz da vaca uma vaca. Sua raça é um acidente de acordo com a metafísica aristotélica.

O termo metafísica não foi criado por Aristóteles, mas por Rodes que no século I a.C. organizando as obras de Aristóteles, classifica alguns escritos como depois da obra de físicameta (depois, acima de) e physis (aquilo que se revela). Rodes concluiu que tais escritos não se encaixavam no livro de Física nem nos de Ética ou Política e, então, simplesmente, os enquadrou na ordem espacial de depois da obra sobre física - daí metafísica.

Tais estudos, que não se encaixam no contexto de outas obras, estudava o ser enquanto ser, isto é, independente de determinações particulares (acidentes). Esses estudos explicavam o ser em geral. Duas obras aristotélicas apresentam esses estudos o livro Da Alma e o batizado por Metafísica. Entre o conteúdo desses livros, as principais informações para nosso viés investigativo são: 1) os sentidos são a primeira fonte de conhecimento - indução ou percepção. E com essa afirmação critica a teoria da reminiscência platônica. 2) a verdade consiste na adequação do conceito à coisa real. 3) A metafísica ou filosofia primeira, como dizia o próprio Aristóteles, não é a primeira quando se fala de conhecer. Ela é o centro de toda filosofia, pois busca as causas mais universais: o ser enquanto ser. 4) A metafísica é fundamental para toda ciência visto que todas as ciências têm um ser como objeto de estudo.

Não obstante, Aristóteles defende a ciência como a superação da doxa; negando a separação platônica entre um mundo sensível e um mundo inteligível pois é pela própria observação do ser (das coisas) que o conhecimento se faz presente. A essa perspectiva chamamos o conhecimento pelas quatro causas: formal, material, eficiente e final. Todo ser pode e deve ser conhecido pelas quatro causas. Por exemplo, o ser caneta. Sua causa formal é o que ela tem em comum com as outras canetas, o que faz com que ela seja o que é; que tende a ser: cilíndrica. A causa material é do que é feita; no caso tinta, plástico etc. A causa eficiente é o que dá movimento ao ser, no caso o operador da máquina de fazer canetas. E a causa final é sua finalidade, ou seja, para que a coisa é feita: para escrever. Essas quatro causas explicam o movimento das coisas e ele é eterno. Por isso a substância de um ser é constituída pela causa material e formal. A essência define o ser. $\mathrm{O}$ acidente são as particularidades.

No exemplo da caneta: vermelha, nova, velha etc. Ato é a coisa como é agora: a caneta e a potência, a capacidade de ser tornar alguma coisa: a tinta e o tubo cilíndrico têm a potência de vir a ser uma caneta. Ou ainda, uma semente carrega em si (potência) de vir a ser árvore (ato). Ao afirmar que todo ser tem em potência sua essência Aristóteles desenvolve uma teoria essencialista. Com efeito, distingue seis formas ou graus de conhecimento: sensação, percepção, imaginação, memória, raciocínio e intuição. Há continuidade entre os graus, porém cada um permite acesso a um aspecto do ser. Seu método é, portanto, demonstrativo com o uso dos silogismos - conjunto de proposições indutivas ou dedutivas em busca de uma verdade lógica.

Marx (1982), Nietzsche (1987) e Sartre (1987) são exemplos de filósofos que recusam a visão aristotélica essencialista. Por exemplo, Sartre (1987) ao dizer que a "existência precede a essência", em sua antropologia, está se opondo a Aristóteles. Marx (1982) ao dizer que "o sujeito se produz pelo trabalho" se opõe igualmente a Aristóteles. Já Nietzsche (1987) radicaliza negando toda e qualquer visão metafísica - essencialista.

É crucial termos em mente a diferença entre o sentido comum de metafísica e o sentido filosófico. No senso comum, metafísica se torna os estudos de milagres ou fatos sobrenaturais, aqueles que ultrapassariam a empiria, a materialidade, a física.

Filosoficamente falando, a partir do próprio Aristóteles, metafísica é o estudo sobre o conhecimento que cada um de nós pode alcançar mediante as quatro causas. Mais precisamente, é a criação de um raciocínio lógico, silogismo, em busca da verdade lógica, a essência de cada 
ser/coisa indubitável; a verdade como dizer, como o resultado de um raciocínio lógico. Nesse sentido, toda a filosofia faz metafísica.

\section{A teoria do conhecimento na Modernidade}

A ênfase na questão do ser desloca-se com a modernidade nascente. Até a Idade Média (do séc. V ao séc. XIV) os filósofos continuaram envoltos na questão do ser. Não era questionado a capacidade humana de conhecer; se partia da certeza que os sujeitos alcançavam de uma forma ou outra a verdade sobre as coisas. Há uma exceção, diga-se de passagem, que é a escola cética cujos filósofos já duvidam da capacidade humana de conhecer, mas predominavam as escolas que afirmavam que conhecer era possível sem problematização.

Duas grandes escolas se destacam na Idade Média; a Patrística e a Escolástica respectivamente retomam o platonismo e o aristotelismo.

A mudança de foco que se dá na modernidade (do séc. XVII ao XVIII) tem a ver tanto com a ruptura com o poder da Igreja Medieval quanto com a ênfase na dúvida do alcance do conhecimento. Enquanto os medievais passam a duvidar do alcance do conhecimento (em relação ao antigos que não duvidavam) visto que a cosmovisão medieval defendia que o conhecimento era dado a alguns iniciados ao bel prazer divino e que meros mortais pecadores não tinham essa dádiva, os filósofos modernos retomam uma visão mais antropológica defendendo a possibilidade humana de conhecer sem descartar a pergunta do alcance e legitimidade desse conhecimento. Em outras palavras, o foco é a consciência da consciência na modernidade e, a pergunta, é se podemos conhecer as coisas - o que para os medievais somente alguns escolhidos tinham o privilégio do saber dado por Deus.

O sujeito que conhece é então o ponto crucial da modernidade e duas perspectivas se destacam em tensão - o racionalismo e o empirismo.

O expoente do racionalismo é o filósofo francês Descartes (1997) e do empirismo os ingleses Bacon (1996) e Locke (2015) e o escocês Hume (1996).

Ainda no século XVIII, Kant (1996) que segundo ele mesmo é despertado por Hume (1996) do sono dogmático, faz uma crítica à metafísica moderna, desenvolvendo o Criticismo, escola que recebe esse nome por razão em julgamento, isto é, sendo crítico com a própria noção de razão, de conhecimento e do valor do conhecimento.

Os métodos elaborados por esses filósofos foram os que, no século XIX, (período contemporâneo) possibilitaram o desenvolvimento da Psicologia como Ciência, por exemplo, apesar de que como veremos a dicotomia psicofísica cartesiana criou dificuldades para as nascentes ciências humanas no século XIX.

O racionalismo coloca a ênfase no papel da razão enquanto o empirismo na experiência. Platão (2015) lança os alicerces para o racionalismo do século XVII ao estabelecer que a alma ou mente ou ainda inteligência possui a razão pela qual alcançamos as ideias perfeitas por meio das lembranças inatas que despertamos pelos sentidos.

A questão fundamental na modernidade é a busca por um método inabalável. Descartes (1997) leva essa busca ao rigor extremo ao desenvolver o que conhecemos como a dúvida metódica: um método que levasse à verdade indubitável considerando a consciência como ponto de partida e dando ênfase na capacidade humana de pensar com o próprio raciocínio em contraposição direta com a visão medieval. Não é por acaso que mais tarde Kant (1996) é expoente do Iluminismo (séc. XVIII) cujo mote é a defesa do pensar por si, sem tutores, fossem esses padres, professores ou o monarca.

O método desenvolvido por Descartes (1997) visava o ideal matemático, a mathesis universalis, que de forma alguma significa aplicar a matemática ao mundo, pois nem seria 
possível visto que Aristóteles já havia afirmado que a matemática nada explica. A mathesis universalis usa o tipo de conhecimento matemático, a saber, a ordem e a medida.

A dúvida metódica segue quatro regras/passos de aplicabilidade: 1) evidência - aceitar só as ideias claras e distintas; 2) análise - dividir as dificuldades em parcelas menores e resolvêlas por parte; 3) ordem - ir dos objetos mais simples aos mais complexos; 4) enumeração fazer revisões gerais para que nada seja esquecido.

Para alcançarmos a primeira regra das quatro a dúvida é o caminho. Por todas as coisas em dúvida como os sentidos e o raciocínio pois ambos podem nos enganar. Ao duvidar de tudo, até do corpo Descartes encontra a primeira verdade, pois clara e distinta. Por esse motivo é o sujeito que duvida que põe fim à cadeia de dúvidas, ao passo que duvidando chega a certeza que mesmo duvidando continua ininterruptamente pensando. Eis a conclusão penso, logo existo que define a racionalidade como um princípio universal de alcance da verdade/conhecimento. Porém, a evidência não resolve toda a questão do conhecimento, pois o mundo que foi posto em dúvida ainda precisa ser retomado. Então Descartes (1997) encontra mais três ideias claras e distintas além do cogito. São elas: 1) as que parecem ter nascido comigo - inatas. 2) As que vieram de fora - experiências sensíveis. 3) as que foram inventadas pelo próprio sujeito imaginação. O cogito, por exemplo, é segundo Descartes (1997) inato, pois não foi inventado pelo sujeito e não vem de fora. Para o filósofo, o cogito já se encontra no espírito como fundamento para a compreensão de outras verdades. Por fim, a prova ontológica é apresentada por Descartes que diz que Deus é também uma ideia inata assim como o cogito. Explica que como somos seres imperfeitos e por conseguimos pensar o perfeito (Deus), então Deus como ser perfeito existe e, como o perfeito não age imperfeitamente, as coisas pensadas clara e distintamente existem, pois, o perfeito não nos enganaria. Deus é a garantia de que o mundo existe de fato.

Há ao menos três consequências da filosofia cartesiana, a primeira é a extrema valorização da razão universal que com sua força própria alcança todas as demais verdades ideias claras e distintas- dogmatismo da razão. A segunda é o dualismo psicofísico que significa a dicotomia corpo-consciência, consciência-mundo. Se estabelecem dois domínios sendo um o corpo objeto de estudo da ciência e a consciência/mente objeto de estudo unicamente da filosofia. Tal distinção trará dificuldades metodológicas as ciências humanas nascentes no século XIX. A terceira é a noção de consciência, o princípio da introspecção. Descartes (1997) não usou o termo consciência, mas o termo cogito para explicar a introspecção de forma metódica.

A segunda perspectiva que se destaca na modernidade é a corrente empirista. Esta opõese ao racionalismo enfatizando o papel das sensações/experiências. Três filósofos se destacam, Bacon (1996), Locke (2015) e Hume (1996).

Bacon (1996) critica a lógica aristotélica, critica a filosofia medieval e insiste na importância da investigação e experimentação. Para tanto apresenta a teoria dos ídolos que se desenvolve em quatro tipos: 1) ídolos da tribo - os preconceitos que circulam na comunidade advindos da generalização e falta de questionamentos. 2) ídolos da caverna - provenientes de cada pessoa, isto é, cada um de nós tem a própria "caverna", as opiniões que nos aprisionam. 3) ídolos do mercado - relações comerciais especificamente a linguagem distorcendo as realidades, a arte de convencer, por exemplo. Nos termos platônicos a linguagem cosmética, que dissimula, ilude e cria falácias. 4) ídolos do teatro - doutrinas filosóficas, os grandes sistemas medievais e as superstições.

Ao nos livrarmos dos ídolos superamos o pensamento degenerado que os ídolos produzem e podemos, então, aplicar o método indutivo, defendido por Bacon (1996) na busca de um conhecimento científico rigoroso. Nesse sentido, para Bacon (1996) investigar a natureza 


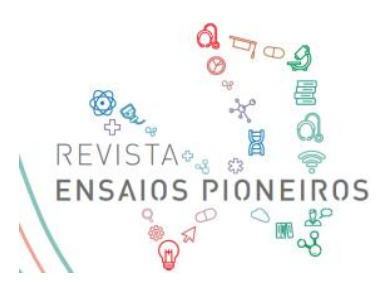

é mais relevante do que as teorias. Com efeito, critica tanto os racionalistas como os próprios empiristas e se coloca como um intermediário de ambos. Com uma metáfora diz:

Os que se dedicaram às ciências foram ou empíricos ou dogmáticos. Os empíricos, à maneira das formigas, acumulam e usam as provisões; os racionalistas, à maneira das aranhas, de si mesmos extraem o que lhes serve a teia. A abelha representa a posição intermediária: recolhe a matéria-prima das flores do jardim e do campo e com seus próprios recursos a transforma e digere. (BACON, 1996, p. 69).

Essa via intermediária é o que o criticismo kantiano seguirá mais adiante e que possibilitará novas perspectivas metodológicas.

John Locke (2015) se dedica tanto a origem como ao alcance do conhecimento. Critica o inatismo cartesiano. Afirma que a alma é como uma tábua rasa ou ainda um papel em branco. Portanto, todo conhecimento se inicia com a experiência. Desta forma a origem das ideias têm duas fontes, a sensação e a reflexão. A sensação é um estímulo externo como o tato, o paladar, etc. A reflexão é um estímulo interno, uma percepção interna resultante do estímulo/percepção externa. Mais precisamente, para Locke (2015) não podemos ter ideias inatas visto que é a experiência que alimenta o intelecto. Assim como afirma que também não podemos conhecer a essência das coisas como defendiam os antigos Heráclito, Parmênides, Platão e Aristóteles.

Para Locke (2015) o comparar, o organizar, o reunir, distinguir e compor as ideias faz parte da percepção interna, a reflexão, que ao combinar as sensações externas as torna ideias complexas como a ideia de identidade, existência, etc. Estas não possuem uma validade objetiva, mas práticas e, por isso, não podemos conhecer as essências visto que o próprio intelecto ao unir ideias simples gera ideias complexas que são nomenclaturas utilizadas para organizar todas as coisas.

O terceiro filósofo que nos interessa nesse percurso é Hume (1996). Este leva adiante as filosofias de Bacon (1996) e Locke (2015) de forma mais cética. Sua teoria defende o método de observação assim como afirma, como um exemplar empirista, que o conhecimento tem origem nas percepções individuais. Estabelece uma distinção entre impressões e ideias. As primeiras são vivas, potentes visto serem sensações originais. As segundas são cópias das sensações e, por isso, mais fracas, menos potentes, desta forma Hume (1996) defende que sentir (impressões) difere-se do pensar (ideias) devido a diferença de intensidade. Conhecer é sinônimo de um ultrapassamento. Chama de hábito a observação de coisas semelhantes que permitem ir além da experiência.

Ainda na modernidade Kant (1996) propõe uma síntese entre as teorias racionalistas e as empiristas dialogando com cada uma e tirando delas as contribuições mais relevantes. A síntese proposta no criticismo kantiano, a nova metafísica, se apresenta como uma crítica aos erros dos inatistas e dos empiristas. Alguns dos pontos mais relevantes da teoria do conhecimento de Kant (1996) são: 1) crítica aos racionalistas e aos empiristas. 2) estabelece dois tipos de conhecimento - a priori e a posteriori. 3) conhecimento a priori tem 2 formas: sensibilidade e entendimento. 4) concorda com os empiristas que a matéria vem de fora e preenche a mente. 5) concorda com os racionalistas que a mente não é uma folha em branco. 6) ponto fraco dos racionalistas e empiristas: "tudo que pensamos vem de nós mesmos" e "tudo o que conhecemos vem dos sentidos". 7) a razão é uma estrutura vazia, uma forma pura sem conteúdo. Essa estrutura (e não os conteúdos) é que é universal.

O criticismo de Kant (1996) afirma, portanto, que conhecer é uma junção entre o que recebemos de fora e o que já existe em nós mesmos, a saber, a razão que é uma estrutura vazia. 
Nenhum conhecimento em nós precede a experiência e todo o conhecimento começa com ela. Mas embora todo o nosso conhecimento comece com a experiência, nem por isso todo ele se origina justamente $d a$ experiência. Pois poderia bem acontecer que mesmo o nosso conhecimento de experiência seja um composto daquilo que recebemos por impressões e daquilo que nossa própria faculdade de conhecimento [...] fornece de si mesma [...]. Tais conhecimentos denominam-se a priori e distinguem-se dos empíricos, que possuem suas fontes a posteriori, ou seja, na experiência. (KANT, 1996, p. 23, grifo do autor).

Acerca do conhecimento a priori Kant (1996) explica que se divide em dois, sensibilidade e entendimento. As formas a priori da sensibilidade são espaço e tempo. Kant (1996) explica que não existem como realidades e, portanto, são formas a priori. Quanto a forma a priori do entendimento são doze categorias que não possuem um conteúdo pois o entendimento é para o filósofo a capacidade de julgar as sensações recebidas pelos sentidos.

Do criticismo kantiano outras teorias se desenvolvem no século XIX. O materialismo e o positivismo de um lado e, de outro, o idealismo.

\section{O nascimento das ciências humanas}

No século XIX os saberes começam a se desligar da Filosofia: tem-se então as ciências humanas como ramos específicos de saber. Surge o que se convencionou a chamar de especializações. Um século antes a astronomia e a física já haviam se desligado da Filosofia. Na sequência, a química se torna autônoma também e se fundamentam em métodos empíricos baseados na experimentação e investigação. A medicina e biologia a seguir fazem o mesmo durante o século XIX. Nesse contexto, as novas ciências humanas, cujo objeto de estudo é o ser humano, usam como exemplo de fazer ciência os métodos utilizados pelas ciências formais e naturais. Gradativamente, os métodos experimentais não são suficientes para um objeto de estudo tão complexo como o ser humano.

Vimos que alguns dos pressupostos da filosofia de Descartes (1997), que como os empiristas passaram a destacar a importância do método, chega no século XIX gerando uma certa dificuldade às ciências humanas que, ao buscar autonomia se veem diante da questão do método, da dualidade psicofísica e precisam, para serem autônomas, resolver esses desafios.

Diferentes filósofos buscam classificar as novas ciências durante essa transição. Dessa forma, temos as ciências formais como a lógica e a matemática; as ciências da natureza ou naturais como a física, a biologia, a química e as ciências mais jovens, as humanas como a psicologia, a história, a linguística, a sociologia, a antropologia e a economia. Atualmente falase em ciências híbridas, pois vão além das classificações prévias por associar diferentes áreas e pensadores como a bioengenharia.

O grande desafio das ciências humanas foi encontrar um método que permitisse o rigor da pesquisa sem desrespeitar o ser humano, que não pode ser simplesmente explicado, mas sim compreendido. Os métodos das ciências formais e naturais se fundam e hipóteses, indução, dedução, analogia e observação. Todavia, com o decorrer do tempo, os pesquisadores das ciências humanas percebem que seu objeto, o ser humano, extrapola tais métodos.

As ciências são uma forma monológica do saber; o intelecto contempla uma coisa e emite enunciado sobre ela. Aí só há um sujeito: o cognoscente (contemplador) e falante (enunciador). A ele só se contrapõe a coisa muda. Qualquer objeto do saber (incluindo o homem) pode ser percebido e estudado coisa porque, como sujeito e permanecendo sujeito, não pode tornar-se mudo; consequentemente, o conhecimento que se tem dele só pode ser dialógico. (BAKHTIN, 2006, p. 400) 
Vale ressaltar que um otimismo bastante generalizado golpeava a todos envolvidos com as ciências formais e naturais defendendo o alcance satisfatório dos métodos para a aplicação da realidade. Nesse sentido, o positivismo de Comte (1982) era muito prestigiado. Porém novas descobertas científicas criam uma fissura nesse otimismo, são elas a física não newtoniana e a geometria não euclidiana. A partir dessas descobertas a crise da ciência se instaura. Mais precisamente, uma visão outra começa a se estabelecer, a que é uma ilusão crer na total infalibilidade das ciências. Eis que a epistemologia passa a ser, com mais especificidade, um moderar dos valores das ciências dada uma visão mais crítica acerca da prática e alcance das mesmas.

\section{A crise da razão}

Desde Hume (1996) e depois com Kant (1996) uma postura mais cética está presente acerca das assertivas vindas dos racionalistas e dos empiristas. Essa postura mais crítica define esses filósofos como os progenitores da crise da razão/subjetividade. Mas que crise é essa? É a dúvida para com o postulado do cogito, como fonte autossuficiente de conhecimento. Em outras palavras, o racionalismo iluminista é colocado em dúvida e sua crença extrema no poder da razão. A esse movimento convencionou-se chamar de Romantismo, a busca por reencatar o mundo, as relações, a produção de conhecimento. Com efeito, a visão de mundo mais pluralista e relacional traz a emoção para um pé de igualdade com a razão. Por esse motivo, a arte é extremamente valorizada. O ser humano em sua totalidade é considerado, a imaginação e a paixão passam a fazer parte da educação estética. Especificamente, a crise da razão é a desconstrução do conceito iluminista de racionalidade desenvolvido na modernidade.

Assim, a partir do século XIX, um movimento de repensar, reiventar e ressignificar a noção de sujeito se intensifica. Mesmo Kant (1996) que é um dos percursores da crise da razão é então questionado quanto o sujeito que é capaz de a partir de si mesmo deliberar de forma autônomo acerca das leis morais. Lévinas (2000) por exemplo dirá que o princípio de autonomia kantiana deve ser substituído pelo princípio da heteronomia, isto é, uma descentralização do eu (ego) para o outro (alter). Parafraseando Bakhtin (2006), "não posso me levantar pelos próprios cabelos", ou seja, o outro é uma necessidade incondicional.

Há três grandes motivos históricos que, segundo Freud (2014), auxiliam no que chamamos de a "morte do sujeito", ou seja, o fim da defesa do sujeito cartesiano (iluminista) autossuficiente. São elas: a descoberta de Copérnico, a teoria da evolução e a teoria do inconsciente. Respectivamente a Terra não ser o centro do universo e a defesa do heliocentrismo gera nas pessoas uma ferida, segundo Freud (2014), uma ferida narcísica, perderam o centro do universo. Darwin com a teoria da evolução desloca o ser humano do centro mais uma vez, do centro animal. A teoria do inconsciente retira o ser humano do próprio centro.

Assim, sem centro, é que se encontra o sujeito. Essa é a crise da subjetividade. Nomes como Kierkegaard (1982), Nietzsche (1987), Marx (ano) e o Freud (2014) são conhecidos como os mestres da suspeita por levarem às últimas consequências as críticas às teorias modernas. Kierkegaard (1982) e a noção de angústia desloca a racionalidade. Afirma que desde Descartes (1997) até Hegel (1982) o ser humano é definido como uma abstração e não um ser existente. Defende a existência como contradições e que a razão somente não é capaz de solucionar. Nietzsche (1987) com a questão da vontade de viver afirma que conhecer é interpretar de forma que atribuir sentido é criar valores, visão pluralista e relativista o que não nos permite conhecer as coisas em si, mas só as interpretações sobre os fatos; crítica severa a todas as metafísicas e defende a arte como o que nos salva da vida. Freud (2014) e o inconsciente desmente os 
racionalistas que a mente é a única fonte segura pela qual reagimos, decidimos etc. Há o inconsciente, maior que a consciência e feito de linguagem simbólica, usando da metáfora para se fazer ouvir e se faz presente, mesmo sem percebemos, em nossas escolhas e comportamentos.

Uma grande resposta à crise das ciências é a fenomenologia husserliana na Contemporaneidade. Essa se constitui como um novo método cujo objetivo enfatizado ao máximo por Husserl (2008) é resolver a crise. A fenomenologia, segundo Husserl (2008) é 1) um novo positivismo; 2) uma crítica o empirismo; 3) uma defesa da intencionalidade da consciência; 4) uma revisão do cogito cartesiano.

A fenomenologia critica o empirismo em sua expressão positivista do século XIX e procura resolver a contradição entre corpo-mente e sujeito-objeto que se arrastava desde Descartes (1997). Nesse sentido, Husserl (2008) entende por fenomenologia o processo pelo qual se examina o fluxo da consciência ao mesmo tempo que é capaz de representar um objeto fora de si. A fenomenologia critica a filosofia tradicional por desenvolver uma metafísica cuja noção de ser é vazia e abstrata, voltada para a explicação/contemplação. Diferentemente, a fenomenologia quer a descrição da realidade e coloca como ponto de partida de sua reflexão o próprio ser humano. No esforço de encontrar o que é dado na experiência, descreve "o que se passa" efetivamente do ponto de vista daquele que vive determinada situação concreta. Por exemplo, ao estabelecer contato com uma outra pessoa, cada um se revela pelos gestos, atitudes, mímica, olhar, enfim, pelas manifestações corporais. Observando o movimento de alguém, não vemos como um ato mecânico, como o de uma máquina, mas como gesto expressivo, nunca apenas corporal, porque o gesto diz algo e nos remete imediatamente à interioridade daquele sujeito.

Um olhar pode significar inúmeras sensações diferentes, como nojo, desprezo, desejo ou amor. O corpo também não é um objeto, um ali simplesmente, mas sim uma corporeidade acessível em partes ao outro eu, com sua singularidade. Da mesma forma que um objeto qualquer tem o sentido que conferimos a ele. O sentido que um caçador atribui a uma arma, por exemplo, é diferente do sentido que um soldado lhe atribuí, ou um assassínio.

Na contramão dos racionalistas, Husserl (2008) afirme que não há uma consciência pura. Pois o legado da fenomenologia é a defesa que consciência é consciência de alguma coisa. Mais precisamente, é intencional. Se opondo também aos empiristas, Husserl (2008) diz que não há objeto em si, já que o objeto é, tem sentido, somente quando lhe atribuímos significado.

A fenomenologia é um método que não perde o rigor, a positividade e, ao mesmo tempo, não perde o sujeito doador de sentido. A experiência é vivida é a base para toda ciência. A experiência é sempre um olhar específico sobre os fatos, as sensações externas e internas.

Para as Ciências Humanas, a fenomenologia é um método de imenso valor, pois desenvolve as regras para se fazer ciência rigorosa e jamais desrespeitar o ser humano, seus valores, crenças, hábitos etc. A redução fenomenológica é, por exemplo, a forma de suspendermos nossos próprios juízos na busca de realmente compreender os juízos dos outros de forma ética e responsável.

\section{O exemplo da Psicologia}

Toda essa reviravolta, o da crise das ciências, desperta ainda mais importância para que as mais jovens das ciências, as Humanas, buscassem um método outro, pois a especificidade dessas ciências é justamente lidar com a imprevisibilidade dos comportamentos humanos. Por isso o desafio inicial era imenso: que método usar? Discute justamente essa diferenciação entre explicar e compreender afirmando que a explicação tem a ver com a intenção, com motivação 
e valorização para dizermos o mínimo. E as ciências humanas, sem perder a objetividade, devem lidar com esse desafio.

Inicialmente, as ciências humanas são marcadas pelos métodos utilizados pelas ciências naturais como o positivismo experimental cuja explicação é causal. Vejamos o exemplo da própria Psicologia que de início é praticamente uma psicofísica por se desenvolver a partir da medicina ao estudar a percepção de forma a quantificar e generalizar as reações a estímulos tal como preconizam os ideais positivistas.

Uma tendência que se fundamenta no método positivista experimental é o Behaviorismo ou Psicologia Comportamental. Skinner (1980) é um dos grandes nomes representantes dessa tendência.

Uma outra tendência que se evidência em contraposição ao positivista e, a partir da distinção entre explicar e compreender, é a hermenêutica cuja definição é uma prática humanista em tensão ao naturalista - experimental. A Gestalt e a Psicanálise são exemplos de tendências que se fundamental na hermenêutica.

Comecemos pelo exemplo da influência do método positivista. O Behaviorismo, exemplo da tendência positivista inicial das Ciências Humanas, desenvolvido dentro da Psicologia, em suas linhas gerais e, em sua perspectiva mais moderada, defende que o comportamento humano pode ser transformado mediante estímulos que geram reações esperadas mediante condicionamentos operantes. Dessa forma, o ideal positivista é respeitado por se buscar uma forma de ser ciência mais mecanicista e determinista.

O exemplo clássico do treinamento de cães: se o cão andar mais rápido que o condutor, o treinador pode puni-lo tirando por uma semana passeios ao parque, por exemplo, ou pode, quando o cão andar lado a lado com o condutor, reforçar dando-lhe um biscoito. As punições visam diminuir um comportamento. Já os reforços visam aumentar um comportamento. Ambos podem ser negativos ou positivos. Negativo retira-se algo, positivo adiciona-se algo.

Nota-se que nesse exemplo de método, quando aplicado ao comportamento humano, a introspeção não é considerada; o que importa é o comportamento e não a consciência considera algo inacessível.

De outro lado, temos a influência do método hermenêutico nas Ciência Humanas. Ainda com o exemplo da Psicologia, temos a Gestlat, com influência da fenomenologia husserliana e a Psicanálise.

A Gestalt busca a compreensão do ser humano em sua totalidade, criticando, por um lado, a tendência empirista por reduzir a percepção a uma sensação isolada e confusa que perde toda a complexidade da percepção que primeiro percebe o todo e não as partes. Por outro lado, critica o racionalismo quando este reduz as sensações a uma síntese realizada pelo pensamento. Contra ambos, afirma que não há diferença entre sensação e percepção. Ao defender as relações, o ser humano é compreendido como um ser relacional que atribui os sentidos dada a intencionalidade da consciência que pode então completar formas (Gestalt) inacabadas, ressiginificando as mesmas, ao depois da percepção total atentar-se às partes, aos detalhes.

No Brasil, Freire (1993) se destacou com o uso da Gestalt. A Gestalt terapia defende que o ser humano é um ser de relações e, como tais são atravessados por $\mathrm{N}$ questões sóciopolíticas que afetam o emocional. Por isso, na perspectiva da Gestalt, a cura se relaciona com a análise de um conjunto de fatores, isto é, tem de se levar em conta o como cada indivíduo vive essas relações que o atravessam. O psicanalista Perls (1977), fundador da Gestalt, defende a metodologia da Gestalt como uma opção outra à Psicologia comportamental (Behaviorismo). Nesse sentido, a Psicologia da Forma (Gestalt) não acredita que exista estímulos sensoriais isolados, por exemplo, mas que há um conjunto inicialmente captado pelo ser humano em sua totalidade. Não obstante, a Gestalt disponibiliza uma visão mais humanizada no 
desenvolvimento da Psicologia ao se debruçar sobre a questão da percepção de modo mais relacional. Como já foi dito, a Gestalt, assim como a Psicanálise são representantes da tendência hermenêutica dentro da Psicologia, daí a importância de ambas.

Dentro da tendência metodologia hermenêutica, pode-se ainda destacar o exemplo da Psicanálise freudiana (2014). A grande contribuição da Psicanálise ao desenvolvimento da Psicologia é justamente a continuação do desenvolvimento da metodologia hermenêutica ou interpretativa. A Psicanálise é uma terapia e uma produção de conhecimento; é uma teoria do inconsciente e da natureza da conduta sexual; é uma compreensão da vida psíquica como um componente qualitativo, isto é, a vida psíquica não pode ser reduzida ao componente quantitativo, de forma que o uso de um método fundado na matematização e generalização não levaria a um lugar diferente daquele encontrado pelo método positivista experimental.

Vale destacar que foram as metodologias com o enfoque mais hermenêuticos como os exemplos citados da Psicanálise e da Gestatl que permitiram à Psicologia, enquanto Ciências Humanas, desenvolver-se de forma mais pluralista, responsável e ética em relação ao seu objeto de estudo que é o ser humano.

A importância do método é crucial, pois cada método permite chegarmos a um determinado lugar. Vimos que, por exemplo, os métodos positivistas, como o Behaviorismo, não chegam ao mesmo lugar que os métodos hermenêuticos, como a Psicanálise e a Gestalt citados aqui. Eis que como Alice no País das Maravilhas (2002), obra escrita em 1865 por Lewis Carrol, pseudônimo de Charles Lutwidge Dodgson, ao perguntar ao gato qual caminho devia seguir e o gato muito espertamente retruca que isso depende de onde ela quer chegar. Alice, perdida, diz que não sabe e o gato Cheshire então conclui que então tanto faz o caminho que ela tomar. Temos uma metáfora da importância de se utilizar o método e, mesmo de uma postura crítica em relação ao método adotado, pois nem todos os métodos conduzirão aos mesmos resultados/compreensões.

\section{CONSIDERAÇÕES FINAIS}

A epistemologia ensina justamente que a ciência não é desinteressada. Que o mito da neutralidade precisa ser evitado e que as relações com a vida, com o mundo da vida (Lebenswelt) para usarmos uma expressão fenomenológica, cunhada por Husserl (2008), não deve jamais ser desconsidera, pois, a perda é a do próprio sentido das ciências. Mediante o percurso traçado, tanto cronológico/histórico quanto essencialista, as metodologias utilizadas desde a origem da Filosofia foram sendo constantemente questionadas e reinventadas. $\mathrm{O}$ uso de um método pode tanto levar a uma crise no âmbito das ciências como trazer soluções para as mesmas. Assim como a escolha de uma ou outra metodologia ditará os limites do conhecimento a ser desenvolvido; o alcance da teoria. Isso evidência que a postura adotada pelo pesquisador, frente as metodologias, deve sempre ser crítica, visando a responsabilidade e o respeito com o objeto de estudos, que no caso das ciências humanas, é o próprio ser humano.

Como vimos com o exemplo da Psicologia, uma ciência desenvolve-se de acordo com os métodos adotados. Isso vale para todas as ciências, pois é o método escolhido que levará a ciência até um certo ponto, que a tornará mais ou menos benéfica, mais ou menos ética e responsável. Mais precisamente, o caminho para o desenvolvimento responsável das Ciências, não só Humanas, começa pela metodologia adotada. $\mathrm{O}$ pesquisador, portanto, precisa estar aberto à discussão metodológica, assim como rever constantemente o método adotado sem perder a clareza de que cada método só pode ir até um certo ponto. Esses são desafios presentes ao pesquisador seja ele, por exemplo, da Psicologia, da Administração ou da Economia, pois a 
estagnação da ciência e a perda de sentido social, ético e político deriva-se do conformismo frente ao método.

\section{REFERÊNCIAS}

ARISTÓTELES. Metafísica. Porto Alegre: Globo, 1997.

BACON, F. Novum Organum. São Paulo: Nova Cultural, 1996. Coleção Os Pensadores.

BAKHTIN, M. Estética da criação verbal. São Paulo: Martins Fontes, 2006.

CARROL, L. Alice no País das Maravilhas. São Paulo: Arara Azul, 2002.

COMTE, A. Augusto Comte. In: VERGES, A., HUISMAN, D. História dos filósofos ilustrada pelos textos. Rio de Janeiro: Freitas Bastos, 1982.

DESCARTES. R. Discurso do método. São Paulo: Nova Cultural, 1997. Coleção Os Pensadores.

FREIRE, R. Soma - uma terapia anarquista. v. III. Rio de Janeiro: Sol e Chuva, 1993.

FREUD, S. Conferências introdutórias sobre psicanálise. São Paulo: Cia das Letras, 2014.

HEGEL, F. Textos de Hegel. In: VERGES, A., HUISMAN, D. História dos filósofos ilustrada pelos textos. Rio de Janeiro: Freitas Bastos, 1982.

HERÁCLITO. Da Natureza. In: Os pré-socráticos. São Paulo: Nova Cultural, 1995. Coleção Os Pensadores.

HUME, D. Tratado da natureza humana. São Paulo: Nova Cultural, 1996. Coleção Os Pensadores.

HUSSERL. E. A Crise da Humanidade Europeia e a Filosofia. $3^{\text {a }}$ ed. Porto Alegre: Edipucrs, 2008. Coleção Filosofia 41.

KANT. I. Crítica da razão pura. São Paulo: Nova Cultural, 1996. Coleção Os Pensadores.

KIERKEGAARD, S. A filosofia trágica de Kierkegaard. In: VERGES, A., HUISMAN, D. História dos filósofos ilustrada pelos textos. Rio de Janeiro: Freitas Bastos, 1982.

LÉVINAS, E. Totalidade e Infinito. Lisboa: Edições 70, 2000. (Coleção Biblioteca de Filosofia Contemporânea).

LOCKE, J. Draft a Do ensaio sobre o entendimento humano. São Paulo: Folha de São Paulo, 2015. Coleção Folha - Grandes Nomes do pensamento.

MARX. K. O Socialismo In: In: VERGES, A., HUISMAN, D. História dos filósofos ilustrada pelos textos. Rio de Janeiro: Freitas Bastos, 1982. 
NIETZSCHE, F. W. A Filosofia na época trágica dos gregos. In: Nietzsche. v. II. São Paulo: Nova Cultural, 1987. Coleção Os Pensadores.

PARMÊNIDES. Sobre a Natureza. In: Os pré-socráticos. São Paulo: Nova Cultural, 1995. Coleção Os Pensadores.

PLATÂO. Mênon. São Paulo: Folha de São Paulo. 2015. Coleção Folha - Grandes Nomes do pensamento.

PERLS, F. Gestalt terapia explicada. 10a ed. São Paulo: Summus, 1977. Coleção Novas Buscas em Psicoterapia.

RICOUER, P. Interpretação e ideologia. Rio de Janeiro: Francisco Alves, 1977.

SARTRE, J. O existencialismo é um humanismo. In: Sartre. São Paulo: Nova Cultural, 1987. Coleção Os Pensadores.

SKINNER, B. F. Sobre o Behaviorismo. São Paulo: Cultrix, 1980.

Publicado em 26/11/2019. 